\title{
Disruption of Yarrowia lipolytica biofilms by rhamnolipid biosurfactant
}

\author{
Devendra H Dusane ${ }^{1,3}$, Sushovan Dam¹, Yarlagadda V Nancharaiah², Ameeta Ravi Kumar ${ }^{1}$, \\ Vayalam P Venugopalan ${ }^{2}$ and Smita S Zinjarde ${ }^{1^{*}}$
}

\begin{abstract}
Background: Yarrowia lipolytica is an ascomycetous dimorphic fungus that exhibits biofilm mode of growth. Earlier work has shown that biosurfactants such as rhamnolipids are efficient dispersants of bacterial biofilms. However, their effectiveness against fungal biofilms (particularly Y. lipolytica) has not been investigated. The aim of this study was to determine the effect of rhamnolipid on a biofilm forming strain of $Y$. lipolytica. Two chemical surfactants, cetyl-trimethyl ammonium bromide (CTAB) and sodium dodecyl sulphate (SDS) were used as controls for comparison.

Results: The methylene blue dye exclusion assay indicated an increase in fungal cell permeability after rhamnolipid treatment. Microtiter plate assay showed that the surfactant coating decreased Y. lipolytica biofilm formation by $50 \%$. Rhamnolipid treatment disrupted pre-formed biofilms in a more effective manner than the other two surfactants. Confocal laser scanning microscopic studies showed that biofilm formation onto glass surfaces was decreased by $67 \%$ after sub-minimum inhibitory concentration (sub-MIC) treatment with rhamnolipids. The disruption of biofilms after rhamnolipid treatment was significant $(P<0.05)$ when compared to SDS and CTAB.
\end{abstract}

Conclusion: The results indicate a potential application of the biological surfactant to disrupt $Y$. lipolytica biofilms.

Keywords: Biofilm, Biosurfactant, CTAB, Rhamnolipid, SDS, Yarrowia lipolytica

\section{Background}

Yarrowia lipolytica earlier referred to as Endomycopsis lipolytica, Saccharomycopsis lipolytica or Candida lipolytica is a hemiascomycetous fungus belonging to the Saccharomycetales order. It is often isolated from environments that are rich in hydrophobic substrates [1]. The organism inhabits soil [2], seawater [3] and refrigerated meat products [4]. The fungus is found in the oral cavity, pulmonary tract and intestines of healthy individuals. It is also an opportunistic pathogen that causes oral candidiasis, candidemia and catheter related infections [5]. From biomedical point of view, the eradication of this organism thus becomes important. The fungus forms biofilms on different surfaces in the presence of a variety of substrates [6]. It is well known that microorganisms in the biofilm mode of growth often resist a variety of antimicrobial agents. There is thus a need to explore alternative means of disrupting biofilms. A variety of chemicals including biocides and surfactants have

\footnotetext{
* Correspondence: smita@unipune.ac.in

${ }^{1}$ Institute of Bioinformatics and Biotechnology, University of Pune, Pune 411 007, India

Full list of author information is available at the end of the article
}

been used to control biofilms [7]. Chemical surfactants find applications in areas of medical care. For example, cetyl trimethyl ammonium bromide (CTAB) is used as a disinfectant in medical settings [8]. Sodium dodecyl sulfate (SDS) is effective by mediating leakage of cellular material from microorganisms [9].

Widespread use of chemical surfactants is discouraged due to their inherent toxicity. In this context, biosurfactants are being favored [10]. The latter group of surfactants offer several advantages in being relatively non-toxic, effective under different environmental conditions and in being biocompatible $[11,12]$. Biosurfactants have been used to disrupt bacterial biofilms $[13,14]$. However the reports on the efficacy of biosurfactants on fungal biofilms are limited [15]. We hypothesized that rhamnolipids may be effective against biofilms of $Y$. lipolytica. The yeast strain used in the current investigation forms biofilms on a variety of water-soluble and -insoluble substrates. The objective of this work was therefore to test the effectiveness of rhamnolipids in (i) preventing biofilm formation and (ii) in disrupting pre-established biofilms of $Y$. lipolytica. The results have been compared with two chemical surfactants.
Ciomed Central

(C) 2012 Dusane et al.; licensee BioMed Central Ltd. This is an Open Access article distributed under the terms of the Creative Commons Attribution License (http://creativecommons.org/licenses/by/2.0), which permits unrestricted use, distribution, and reproduction in any medium, provided the original work is properly cited. 


\section{Results and discussion}

Minimum inhibitory concentration (MIC) and minimum fungicidal concentration (MFC) values of surfactants

The chemical and biological surfactants displayed antifungal activity against the cells of Y. lipolytica NCIM 3589. Rhamnolipid and CTAB displayed a minimum inhibitory concentration (MIC) of $5 \% \pm 0.1 \mathrm{w} / \mathrm{v}$ and minimum fungicidal concentration (MFC) value $>10 \% \pm 0.1 \mathrm{w} / \mathrm{v}$, while SDS showed MIC and MFC values of $0.62 \% \pm 0.05 \mathrm{w} / \mathrm{v}$. SDS was more effective as an antifungal agent compared to rhamnolipids and CTAB. This anionic surfactant is known to possess detergent and antimicrobial properties [16]. The surfactant permeabilizes cells by targeting the cytoplasmic membranes and by affecting membranebound enzymes [16]. Rhamnolipids are anionic biosurfactants that disrupt cells by interacting with the phospholipid components of the biological membranes $[17,18]$. Rhamnolipids derived from Pseudomonas aeruginosa are known to possess antifungal activity against some plant pathogenic fungi such as Cercospora kikuchii, Cladosporium cucumerinum, Colletotrichum orbiculare, Cylindrocarpon destructans, Magnaporthe grisea and Phytophthora capsici [19]. The rhamnolipids inhibited spore germination and prevented hyphal growth in $P$. capsici at concentrations of $50 \mu \mathrm{g} \mathrm{ml}{ }^{-1}$. A cationic surfactant, CTAB displayed lower antifungal activity towards $Y$. lipolytica as compared to SDS or rhamnolipids. In the present investigation, lower antifungal activity of CTAB could be a result of reversal of fungal cell surface charge and not due to cell lysis, as observed with SDS [9].

Increase in cell permeability after treatment with surfactants Rhamnolipids display antimicrobial and surfactant properties [14]. They are known to increase cell permeability of P. aeruginosa, Escherichia coli and Bacillus subtilis [20]. In the present case, rhamnolipids were found to be less effective in increasing the cell permeability of $Y$. lipolytica, as compared to SDS. SDS displayed higher permeability even at concentrations lower than MIC values (Figure 1, Table 1). In Figure 1, white arrows point towards non-permeabilized cells and the black arrows depict permeabilized cells. The increase in permeability observed after treatment with SDS may be due to the possible formation of molecular aggregates in the membrane and creation of trans-membrane pores [21]. CTAB was least effective in permeabilizing cells. This reduced permeability of the dye could be due to the robust nature of the fungal cell walls [22].

\section{Effect of surfactant pre-coating on biofilm growth}

Anti-adhesive activity of microbial surfactants has been reported earlier $[11,14,23]$. Pre-coating of microtiter plate wells with the surfactants effectively reduced the development of $Y$. lipolytica biofilms. Adhesion of $Y$. lipolytica cells to the microtiter plate wells was inhibited to $50 \%$ with rhamnolipids at MIC concentration (5\%) (Figure 2, asterisk). Rhamnolipids showed significant anti-adhesive ability $(\mathrm{P}<0.05)$ as compared to CTAB that inhibited $29 \%$ at MIC value of $5 \%$ (Figure 2, black arrow). With SDS at MIC $(0.625 \%)$ the inhibition was less than $10 \%$ (Figure 2, black triangle). Rhamnolipids are known to decrease Listeria monocytogenes attachment when preconditioned onto Polytetrafluoroethylene (PTFE) surfaces [24]. We have also recently demonstrated the ability of rhamnolipids in disrupting Bacillus pumilus biofilms by removing exopolymeric substances [14]. SDS is known to display anti-adhesive ability by affecting the hydrophobic bonds that help in attachment of cells to the surfaces [25]. In the present study however, SDS showed lower anti-adhesive ability than rhamnolipids. Although CTAB is reported to bind to the negatively charged microbial surfaces, alter their surface charge and prevent the binding of the cells to the surfaces [26], this surfactant was not as effective in preventing $Y$. lipolytica adhesion. In the present study, the anti-adhesive effect of rhamnolipids was found to be
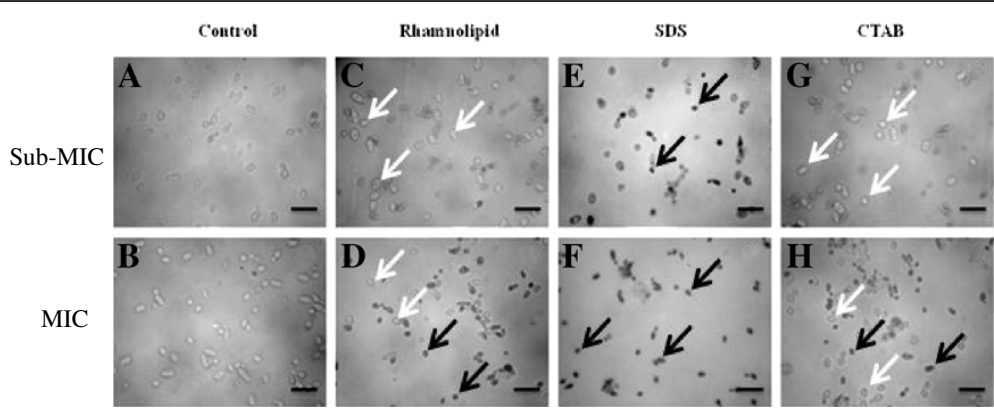

Figure 1 Morphological features of $Y$. lipolytica NCIM 3589 cells. Control cells (A and B); after treatment with rhamnolipid (C, D); SDS (E, F); and CTAB $(\mathbf{G}, \mathbf{H})$ at sub-MIC and MIC concentrations, respectively, for $1 \mathrm{~h}$. The sub-MIC and MIC concentrations of $2.5 \%$ and $5 \% \mathrm{~W} / \mathrm{V}$ respectively for rhamnolipid and CTAB and $0.3 \%$ and $0.62 \% \mathrm{w} / \mathrm{v}$ concentration of SDS were used. Bar indicates $10 \mu \mathrm{m}$. The upper panel indicates sub-MIC concentrations and lower panel shows MIC concentrations of the surfactants tested. White arrow shows non-permeability of methylene blue within the yeast cells whereas the black arrow depicts increase in cell permeability and uptake of the dye after treatment with surfactants. 
Table 1 Methylene blue dye exclusion by $Y$. lipolytica cells post treatment with $1 / 2$ MIC and MIC of surfactants for $1 \mathrm{~h}$

\begin{tabular}{lll}
\hline Surfactants & Cells stained at $\mathbf{1} \mathbf{2}$ MIC (\%) & Cells stained at MIC (\%) \\
\hline Rhamnolipid & $20 \pm 2$ & $25 \pm 2$ \\
SDS & $70 \pm 4$ & $95 \pm 2$ \\
CTAB & $7 \pm 2$ & $14 \pm 4$ \\
\hline
\end{tabular}

significantly higher as compared to SDS and CTAB suggesting the potential of rhamnolipids as anti-adhesive agents in the treatment of fungal biofilms.

\section{Disruption of preformed biofilms of $Y$. lipolytica}

The preformed biofilms of $Y$. lipolytica were treated with the surfactants for 1, 2 or $3 \mathrm{~h}$. Biofilms of Y. lipolytica formed for 3 days in microtiter plate wells were disrupted effectively (55\% with rhamnolipid, 35\% with CTAB and $40 \%$ with SDS at respective MIC values) within $1 \mathrm{~h}$ of treatment with the surfactants (Figure 3a asterisk, arrow and triangle, respectively). At concentrations of surfactants lower than MIC, rhamnolipid displayed effective dispersion of biofilms (46\%), followed by SDS (38\%) and CTAB (25\%). At higher concentrations ( $>2.5 \%)$, the effect of SDS was slightly better than that of the rhamnolipid. However, over a period of time, the efficacy of rhamnolipids was found to be similar to that of SDS (Figure 3b and $3 c)$. CTAB was less effective in controlling biofilms, possibly due to its chemical interaction with fungal proteins present in the exopolymeric matrix [27]. There are also reports that show the efficacy of CTAB over SDS in controlling bacterial biofilms [27]. The present study showed that $Y$. lipolytica biofilms could be removed effectively by SDS compared to CTAB.
Biofilms of $Y$. lipolytica formed on glass slides for 3 days were disrupted by using sub-MIC concentrations of the surfactants. The concentrations of surfactants were selected on the basis of the microtiter plate results. Rhamnolipids effectively disrupted $Y$. lipolytica biofilms on glass surfaces upto $76 \%$ with SDS, $53 \%$ and with CTAB $38 \%$ disruption was observed. The disruption with rhamnolipids was found to be statistically significant $(\mathrm{P}<0.05)$ as compared to SDS and CTAB. Rhamnolipids have earlier shown to be effective against bacterial biofilms [14], however there are limited reports on their effect on fungal biofilms. In the present study rhamnolipids were found to be effective in disrupting biofilms of $Y$. lipolytica compared to SDS and CTAB, suggesting their potential application as biofilm disrupting agents (Figure 4). The effectiveness of rhamnolipids against biofilms even at low concentrations makes them a good candidate for therapeutic applications.

\section{Conclusions}

Rhamnolipids have potential to disrupt $Y$. lipolytica biofilms as compared to chemical surfactants, SDS and $\mathrm{CTAB}$. The results suggest potential of rhamnolipid biosurfactants as anti-adhesive and preformed biofilm disrupting agents and their possible role in the treatment of fungal infections.

\section{Methods}

\section{Culture and growth conditions}

A biofilm forming strain of $Y$. lipolytica NCIM 3589 was used in the experiments [6]. Cells were grown in $50 \mathrm{ml}$ YEPD broth (yeast extract $0.3 \%$, peptone $0.5 \%$ and dextrose $1 \%$ ) in $250 \mathrm{ml}$ Erlenmeyer flasks at $30^{\circ} \mathrm{C}$ on shaker at $150 \mathrm{rpm}$ for $24 \mathrm{~h}$.

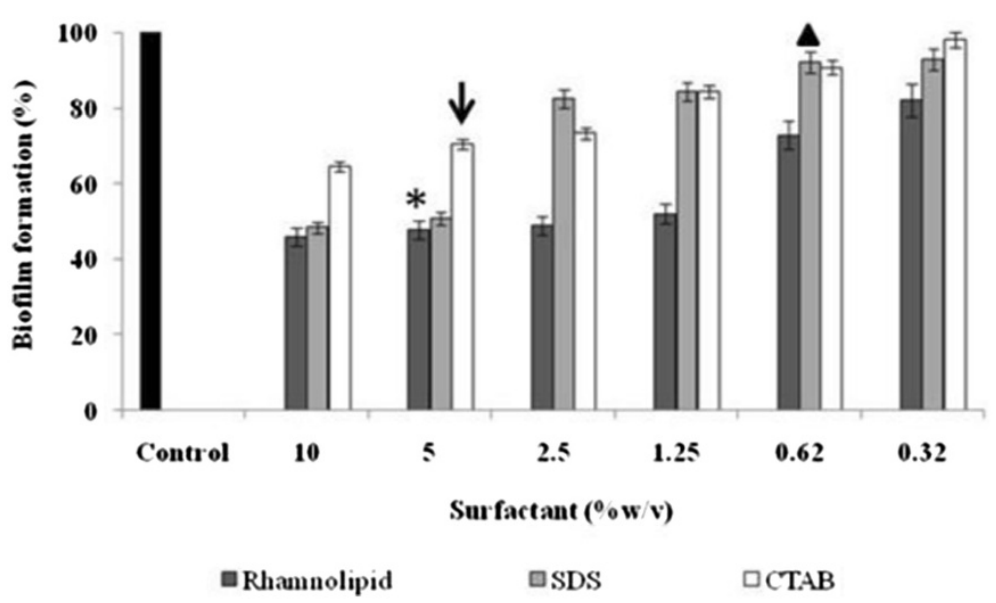

Figure 2 Inhibition of $Y$. lipolytica NCIM 3589 biofilms by surfactants. Observations in microtiter plate wells after pre-coating with different concentrations of rhamnolipid, SDS or CTAB. Control indicates biofilm formation by Y. lipolytica in microtiter plates untreated with the surfactants. The OD values are normalized with reference to control (considered as 100\%). Where asterisk $(*)$, triangle $(\mathbf{\Lambda})$ and arrow $(\downarrow)$ indicates MIC concentrations of rhamnolipid, SDS and CTAB respectively. 

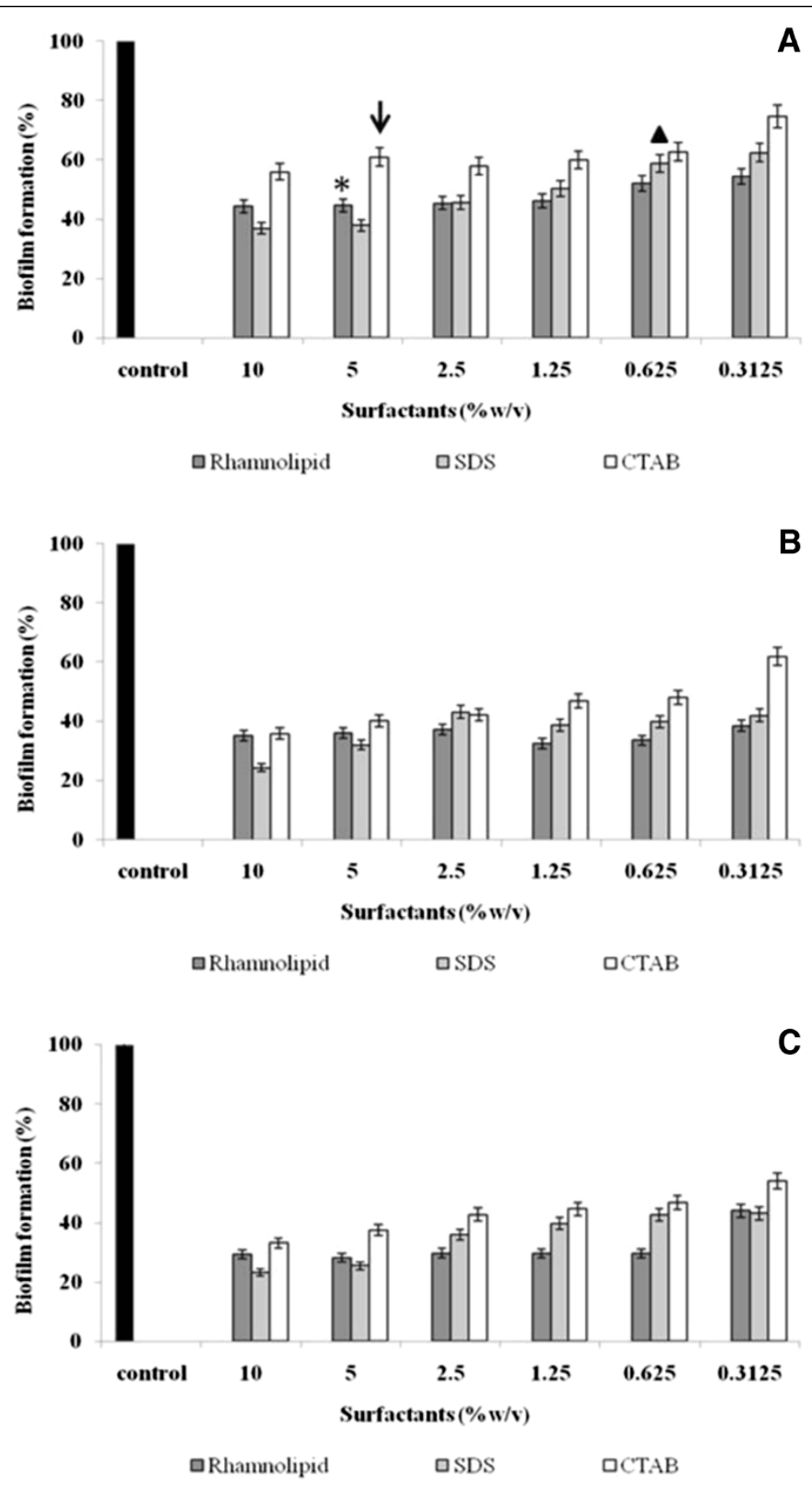

Figure 3 Effect of surfactants on preformed biofilms of $Y$. lipolytica NCIM 3589. Observations with rhamnolipid, SDS and CTAB after (A) $1 \mathrm{~h}$ (B) $2 \mathrm{~h}$ and $(\mathbf{C}) 3 \mathrm{~h}$ of incubation. Where, star $\left(^{*}\right)$, triangle $(\mathbf{\Lambda})$ and arrow $(\downarrow)$ indicates MIC concentrations of rhamnolipid, SDS and CTAB respectively.

\section{Chemical agents}

Rhamnolipid biosurfactant, a mixture of mono and dirhamnolipids was used [14]. CTAB and SDS were obtained from HiMedia, India. Stock solutions of the surfactants were prepared in sterile distilled water; filter sterilized through $0.22 \mu$ filters and used further for experimentation.

\section{Determination of MIC and MFC values}

MIC of surfactants against $Y$. lipolytica was determined by broth microdilution assay in sterile 96 well microtiter plates (Tarsons, India) [14]. Briefly, pre-grown (36 h) cells of $Y$. lipolytica were added to the microtiter plate wells containing YEPD medium to achieve the final cell 


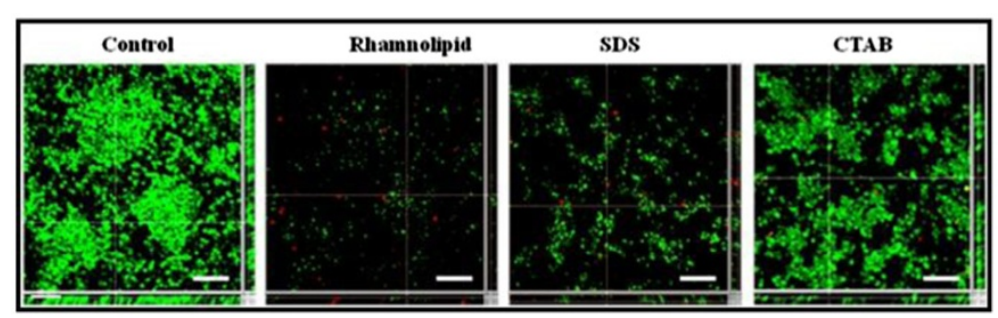

Figure 4 Representative CLSM images of Y. lipolytica NCIM 3589 biofilms. Observations of control cells and cells treated with sub-MIC concentration of rhamnolipid $(2.5 \% \mathrm{w} / \mathrm{v})$, SDS $(0.3 \% \mathrm{w} / \mathrm{v})$ and CTAB $(2.5 \% \mathrm{w} / \mathrm{v})$ for $1 \mathrm{~h}$, showed live cells stained with SYTO9 and dead cells stained with PI. Bar indicates $30 \mu \mathrm{m}$.

numbers of $1 \times 10^{7}$ cells $\mathrm{ml}^{-1}$. Surfactants (rhamnolipid, SDS and CTAB) were added to these wells at varying concentrations $(0.005$ to $10 \% \mathrm{w} / \mathrm{v})$. The final volume in the microtiter plate wells was maintained to $200 \mu \mathrm{l}$. The plates were incubated at $30^{\circ} \mathrm{C}$ for $48 \mathrm{~h}$ and after the incubation period, growth in presence of the surfactants was estimated as $\mathrm{OD}_{600}$ using a microtiter plate reader (Multiskan, Thermo Lab systems). Wells without surfactants and those lacking the cells were used as controls. The MFC was determined by streaking the culture grown in presence of different concentrations of the biosurfactant onto YEPD agar plates. The plates were incubated for $48 \mathrm{~h}$ and growth was recorded. Minimum inhibitory concentration (MIC) was determined as the lowest concentration without visible growth and the minimum fungicidal concentration (MFC) as the lowest concentration showing no growth on the agar surface. The experiments were performed in triplicate and the mean values were obtained.

\section{Fungal cell permeability analysis by methylene blue dye exclusion}

In order to determine the effect of surfactants on yeast cell permeability, the method of Hammer et al. (2004) was followed with few modifications [28]. Y. lipolytica cells were grown in YEPD broth for $24 \mathrm{~h}$. The cells were harvested, washed twice with sterile distilled water and resuspended in PBS to achieve $10^{7}$ cells $\mathrm{ml}^{-1}$. Aliquots were distributed equally in sterile flasks containing rhamnolipids, SDS or $\mathrm{CTAB}$ at MIC and sub-MIC concentrations. The flasks were incubated at $30^{\circ} \mathrm{C}$ under shaking conditions. After $1 \mathrm{~h}, 100 \mu \mathrm{l}$ of these samples were withdrawn and to this $20 \mu \mathrm{l}$ of $0.05 \% \mathrm{w} / \mathrm{v}$ methylene blue (prepared in sterile distilled water) was mixed and incubated for $1 \mathrm{~min}$ at room temperature. Methylene blue stained samples were placed onto the glass slides and the cells were examined microscopically by using an Axio Scope-A1 microscope with a photographic attachment (ProgRes ${ }^{\circledR}$ Capture Pro 2.7) at a magnification of $400 \times$. A minimum of 500 cells in consecutive visual fields were examined and the percentage stained cells was calculated manually [28]. Cells untreated with the surfactants were used as controls for the experiment.

\section{Effect of surfactant pre-coating on biofilm formation}

Surfactants $(100 \mu \mathrm{l}$ containing $0.3-10 \% \mathrm{w} / \mathrm{v}$ concentration) were added to wells of the polystyrene microtiter plates and incubated for $12 \mathrm{~h}$ at $4^{\circ} \mathrm{C}$ to facilitate effective coating [23]. After the incubation period, the wells were emptied of residual surfactants, rinsed with sterile distilled water and air dried in a laminar air flow for $5 \mathrm{~min}$. Cells $\left(100 \mu\right.$ l containing $\sim 10^{7}$ cells $\left.\mathrm{ml}^{-1}\right)$ of $Y$. lipolytica were added to the microtiter plate wells and incubated for $24 \mathrm{~h}$ at $30^{\circ} \mathrm{C}$. After the incubation period, the microtiter plate wells were emptied of the non-adherent cells and the plates were rinsed with sterile distilled water. The adherent cells were quantified by using the crystal violet assay [14]. All experiments were carried out in triplicates with two biological replicates and average values indicating standard deviation are presented here.

\section{Disruption of preformed biofilms}

$Y$. lipolytica biofilms were allowed to form in sterile polystyrene 96 well microtiter plate wells for 3 days [6]. After the incubation period, planktonic cells were removed and varying concentrations $(0.3-10 \% \mathrm{w} / \mathrm{v})$ of rhamnolipid, SDS and $C T A B$ were individually added to the wells. The plates were further incubated at $30^{\circ} \mathrm{C}$ for 1,2 or $3 \mathrm{~h}$. After each time interval, the microtiter plate wells were emptied of the non-adherent cells and rinsed with sterile distilled water. The residual biofilms were quantified by using the standardized crystal violet assay [14]. All experiments were performed in triplicates with two biological replicates and the data is presented as average values indicating standard deviation.

\section{Confocal laser scanning microscopy (CLSM)}

$Y$. lipolytica biofilms were formed on sterile microscopic glass slides as described earlier [29]. Cells were inoculated in sterile petriplates containing the growth medium (YEPD) to reach a cell density of $1 \times 10^{7}$ cells $\mathrm{ml}^{-1}$. Sterile microscopic glass slides were placed in the petriplates 
and incubated on a rocker at $30^{\circ} \mathrm{C}$ for 3 days. After the growth period, glass slides were removed and placed in another petri dish containing growth medium supplemented with $0.3 \% \mathrm{w} / \mathrm{v}$ concentration of rhamnolipids, SDS or CTAB. Biofilms were treated for $1 \mathrm{~h}$ in presence of the surfactants. Untreated biofilms were used as controls and the biofilm coverage thus obtained was considered to be $100 \%$. The slides were removed, rinsed twice with sterile distilled water and stained with LIVE/DEAD BacLight staining kit containing SYTO9 and Propidium Iodide (PI) (Molecular Probes, Eugene, Oregon, US) as per the manufacturer's instructions. The slides were observed under a CLSM (SP2 AOBS, Leica Microsystems, Germany). A $63 \times 1.2$ NA water immersion objective was used with $488 \mathrm{~nm}$ Ar laser excitation and 500$640 \mathrm{~nm}$ band pass emission setting. Multiple (20) images were scanned and analyzed using the image processing software; ImageJ (http://rsb.info.nih.gov/ij). The observations were made in triplicates and representative images are presented here.

\section{Statistical analysis}

The effect of rhamnolipid on biofilms was analyzed statistically by the Students $t$-test and treatments were considered significantly different if $\mathrm{P} \leq 0.05$.

\begin{abstract}
Abbreviations
CTAB: Cetyl-trimethyl ammonium bromide; SDS: Sodium-dodecyl-sulphate; MIC: Minimum inhibitory concentration; MFC: Minimum fungicidal concentration; PTFE: Polytetrafluoroethylene; NCIM: National collection of industrial microorganisms; YEPD: Yeast extract peptone dextrose; OD: Optical
\end{abstract} density; CLSM: Confocal laser scanning microscopy.

\section{Competing interests}

The authors declare that they have no competing interests.

\section{Authors' contribution}

DHD and SD performed the experimental work and acquired the data. YVN performed the CSLM analysis. VPV and SSZ made contributions to conception and design. ARK analyzed and interpreted the data. DHD, SD, VPV and SSZ have been involved in drafting the manuscript and revising it critically for important intellectual content. All authors have given final approval for the version to be published.

\section{Authors' information}

DHD is a currently a postdoctoral fellow at McGill University. SD is a postgraduate student at Institute of Bioinformatics and Biotechnology (IBB). YVN and VPV are Scientists at Biofouling and Biofilm Processes Section, Chemistry Group, Bhabha Atomic Research Centre, BARC Facilities, Kalpakkam, Tamil Nadu 603102 India. ARK and SSZ are Associate Professors at IBB, University of Pune, Pune 411007 India.

\section{Acknowledgements}

DD would like to acknowledge the research fellowship provided under the Bhabha Atomic Research Centre (BARC) and University of Pune collaborative research programme.

\section{Author details}

${ }^{1}$ Institute of Bioinformatics and Biotechnology, University of Pune, Pune 411 007, India. ${ }^{2}$ Biofouling and Biofilm Processes Section, BARC Facilities, Kalpakkam 603 102, India. ${ }^{3}$ Present address: Biocolloids and Surfaces Laboratory, Department of Chemical engineering, McGill University, Montreal, QC, Canada.
Received: 29 May 2012 Accepted: 27 July 2012

Published: 27 July 2012

\section{References}

1. Barth G, Gaillardin C: Physiology and genetics of the dimorphic fungus Yarrowia lipolytica. FEMS Microbiol Rev 1997, 19:219-237.

2. Margesin R, Schinner F: Bioremediation of diesel-oil-contaminated alpine soils at low temperatures. Appl Microbiol Biotechnol 1997, 47:462-468

3. Zinjarde SS, Pant A: Hydrocarbon degraders from a tropical marine environment. Mar Pollut Bull 2002, 44:118-121.

4. Kurtzman CP: Yarrowia van de Walt and von Arx. Descriptions of telomorphic ascomycetous genera and species. In The yeasts: a taxonomic study. 4th edition. Edited by Fell JW. Amsterdam: Elsevier Science; 1998:420-421.

5. Agarwal S, Thakur K, Kanga A, Singh G, Gupta P: Catheter-related candidemia caused by Candida lipolytica in a child with tubercular meningitis. Indian J Patho Microbiol 2008, 51:298-300.

6. Dusane DH, Nancharaiah $\mathrm{V}$, Venugopalan VP, Kumar AR, Zinjarde SS: Biofilm formation by a biotechnologically important tropical marine yeast isolate, Yarrowia lipolytica NCIM 3589. Water Sci Technol 2008, 58:1221-1229.

7. Chen $X$, Stewart PS: Biofilm removal caused by chemical treatments. Wat Res 2000, 34:4229-4233.

8. McDonnell G, Russell AD: Antiseptics and disinfectants: activity, action, and resistance. Clin Microbiol Rev 1999, 12:147-179.

9. Vieira DB, Carmona-Ribeiro AM: Cationic lipids and surfactants as antifungal agents: mode of action. J Antimicrobial Chemother 2006, 58:760-767.

10. Banat IM, Franzetti A, Gandolfi I, Bestetti G, Martinotti MG, Fracchia L, Smyth TJ, Marchant R: Microbial biosurfactants production, applications and future potential. Appl Microbiol Biotechnol 2010, 87:427-444.

11. Rodrigues L, Banat IM, Teixeira J, Oliveira R: Biosurfactants: Potential applications in medicine. J Antimicrob Chemother 2006, 57:609-618

12. Kosaric N: Biosurfactants and their application for soil bioremediation. Food Technol Biotechnol 2001, 39:295-304.

13. Rivardo F, Turner RJ, Allegrone G, Ceri H, Martinotti MG: Anti-adhesion activity of two biosurfactants produced by Bacillus spp. prevents biofilm formation of human bacterial pathogens. Appl Microbiol Biotechnol 2009, 83:541-553.

14. Dusane DH, Nancharaiah YV, Venugopalan VP, Zinjarde SS: Rhamnolipid mediated disruption of marine Bacillus pumilus biofilms. Colloids Surf B: Biointerfaces 2010, 81:242-248.

15. Busscher HJ, Van Hoogmoed CG, Geertsema-Doornbusch Gl, van der KuijlBooij M, van der Mei HC: Streptococcus thermophilus and its biosurfactants inhibit adhesion by Candida spp. on silicone rubber. App/ Environ Microbiol 1997, 63:3810-3817.

16. Glover ER, Smith RR, Jones VM, Jackson KS, Rowlands CC: An EPR investigation of surfactant action on bacterial membranes. FEMS Microbiol Lett 1999, 177:57-62.

17. Ortiz A, Aranda FJ, Teruel JA: Interaction of dirhamnolipid biosurfactants with phospholipid membranes: a molecular level study. Adv Exp Med Biol 2010, 672:42-53.

18. Aranda FJ, Espuny MJ, Marques A, Teruel JA, Manresa A, Oritz A: Domain formation by a Rhodococcus sp. biosurfactant trehalose lipid incorporated into phosphatidylcholine membranes. Langmuir 2007, 23:2700-2705

19. Kim BS, Lee JY, Hwang BK: In vivo control and in vitro antifungal activity of rhamnolipid B, a glycolipid antibiotic, against Phytophthora capsici and Colletotrichum orbiculare. Pest Management Sci 2000, 56:1029-1035.

20. Sotirova AV, Spasova DI, Galabova DN, Karpenko E, Shulga A: Rhamnolipidbiosurfactant permeabilizing effects on Gram-positive and Gramnegative bacterial strains. Curr Microbiol 2008, 56:639-644.

21. King AT, Davey MR, Mellor IR, Mulligan BJ, Lowe KC: Surfactant effects on yeast cells. Enzyme Microbial Technol 1991, 13:148-153.

22. Komor E, Weber H, Tanner W: Greatly decreased susceptibility of nonmetabolizing cells towards detergents. Proc Natl Acad Sci USA 1979, 76:1814-1818.

23. Das $P$, Mukherjee $M$, Sen $R$ : Antiadhesive action of a marine microbial surfactant. Colloids Surf B: Biointerfaces 2009, 71:183-186.

24. Meylheuc T, van Oss CJ, Bellon-Fontaine MN: Adsorption of biosurfactant on solid surfaces and consequences regarding the bioadhesion of Listeria monocytogenes LO28. J Appl Microbiol 2001, 91:822-832. 
25. Nesbitt WE, Doyle RJ, Taylor KG: Hydrophobic interactions and the adherence of Streptococcus sanguis to hydroxyapatite. Infect Immun 1982, 38:637-644.

26. Schott $H$, Young YC: Electrokinetic studies of bacteria II: effect of cetyltrimethylammonium bromide on Streptococcus faecalis. J Pharm Sci 1972, 61:762-765.

27. Simoes M, Simoes LC, Machado I, Pereira MO, Vieira MJ: Control of flowgenerated biofilms using surfactants-evidence of resistance and recovery. Food Bioproducts Process 2006, 84:338-345.

28. Hammer KA, Carson CF, Riley TV: Antifungal effects of Melaleuca alternifolia (tea tree) oil and its components on Candida albicans, Candida glabrata and Saccharomyces cerevisiae. J Antimicrobial Chemother 2004, 53:1081-1085.

29. Dusane DH, Rajput JK, Kumar AR, Nancharaiah W, Venugopalan VP, Zinjarde SS: Disruption of fungal and bacterial biofilms by lauroyl glucose. Lett Appl Microbiol 2008, 47:374-379.

doi:10.1186/2046-9063-8-17

Cite this article as: Dusane et al.: Disruption of Yarrowia lipolytica biofilms by rhamnolipid biosurfactant. Aquatic Biosystems 2012 8:17.

\section{Submit your next manuscript to BioMed Central and take full advantage of:}

- Convenient online submission

- Thorough peer review

- No space constraints or color figure charges

- Immediate publication on acceptance

- Inclusion in PubMed, CAS, Scopus and Google Scholar

- Research which is freely available for redistribution 